\title{
Valuation Ecologies and Academic Governance
}

\author{
Kristian Kreiner
}

\begin{abstract}
University managers are forced to assume responsibility for more and more aspects of academic life. This essay focuses on academic publishing and how deans and department heads attempt to manage the volume and quality of publications at their university because others, including politicians and scholars, rate the quality and effectiveness of the university on their publication output. How managers assume and practice this responsibility for academic publishing may seem self-evident but proves to hide both paradoxes and loopholes. Reflections build on an empirical illustration derived from the adoption of a conventional publication strategy. The implementation of this strategy is fueled by a large dose of strategic expediency. However, such expediency incurs costs related to impression management when managers need to show a sense of command in response to a disappointing performance. Both material costs (time and money) and symbolic costs (demonstrating allegiance to an embarrassingly naive conception of academia) are incurred. Exactly because management is exercised on the premise of an embarrassingly naive conception of academia, the presumed coercive forces are exceedingly loose and ineffective. The room for value judgment at all levels of the university organization is not closed but rather enshrined (for good or bad) behind a façade of objectivity and factuality.
\end{abstract}

Keywords: strategic expediency; value judgment; governance; publication strategy; useless arithmetic

Kristian Kreiner is a professor emeritus at Copenhagen Business School, Department of Organization.

(C) 2021 The author (cc) BY This work is licensed under a Creative

Commons Attribution 4.0 International License.

https://doi.org/10.3384/VS.2001-5992.2021.8.2.89-102

Hosted by Linköping University Electronic press

http://valuationstudies.liu.se 


\section{Valuation ecologies in universities}

We all live in multiple ecologies of valuation. In academia, "we conduct valuations, we are valued, and we manage valuation practices" (José Ossandón 2021). Moments of valuation are pervasive and fundamental to academic work. Often, such moments are complicated by an awareness of the fact that any act of valuation will be, directly or indirectly, valued by others. Thus, editors rank reviewers, university managers rate teachers' grading of student performance (Alvesson and Szkudlarek 2021), and authors judge the competence of their peer reviewers (Tsang 2013; Willmott forthcoming). Of special interest here, valuation at one level translates into new moments of valuation at aggregate levels of an organization. When the publication performance of individual scholars, departments, universities, and nation-states is made an object of valuation, these performances inevitably end up on the agenda of university managers and politicians. Since we collectively hold managers and politicians accountable for the outcomes of such valuation, they are forced to act in ways that appear to enhance underlying performance. Such managerial and political action has implications for individual scholars as well as for universities, but not necessarily in any intended manner.

The field of valuation studies has traced the important consequences of the dispersed ecologies of valuation in academia. Supposedly, immediate success and one's career depend on scoring well in the eyes of removed and impersonal rating agents - a supposition that empowers extrinsic perspectives on academic virtues and the role of universities. Both teaching curricula and research agendas will predictably give sway to the criteria on which ratings and rankings are based, not because of trust in the valuation methods and the fairness of their results but because of strategic expediency.

To illustrate such strategic expediency, I will focus on the publication strategy that my university has adopted. At face value, this publication strategy seems innocent, but managerially it harbors a foul irony that I will expose below. I will turn this publication strategy into an illustration of the absurdities of management in modern society since simple and useless arithmetic (see Pilkey and Pilkey-Jarvis (2007) and Baum (2011)) seems to rule institutions and organizations. In short, I claim that we suffer from the ecologies of valuation because we live in a society of governance that rests and depends on all kinds of valuation heuristics, ratings, and rankings.

Naturally, there are explicit and implicit costs (including opportunity costs) in governing universities in this way. Many such costs are derived from the need to ceremonially pledge allegiance to this notion of governance, despite its rather obvious limits and pretentious nature. However, I will conclude by arguing that such 
falseness also leaves room for experimentation and maneuvering in search of meaning and success.

\section{Empirical illustration: the publication strategy}

The Department of Organization (IOA) at Copenhagen Business School (CBS) adopted the IOA Publication Strategy 2019, which is posted on the CBS intranet ${ }^{1}$. In a preamble to the strategy document, the department reconfirms the purpose of publishing and the priority of quality over quantity. The dramatic changes taking place in the publishing world are also recognized. Then, the document continues:

... in a response to a recent request [by the Dean of Research], and to give an indication of our shared research interests, we have assembled a list of key journals, the "IOA15 journal list."2 The list is not meant to exclude, but to guide and inspire faculty, as well as inform stakeholders interested in the composite research profile of the department.

The aim is to accelerate the rate of publication within the IOA15 journal list, which is why annual statistics will be collected to monitor the progress. The implementation of the strategy will include holding:

“... regular publishing seminars for faculty, including publication options for junior faculty, focusing on publishing in selected journals and at distinguished publishing houses. Among other things, this includes the invitation of editors from the IOA15 list for 'tips and clues' and [the] exchange of ideas."

At first, the codification of an IOA15 journal list seems to be a banal choice with little strategic import. The department had recently merged with another department, and the number of relevant journals on the list for organizational scholars was ten at best. Five of these are rated $4 *$, three rated 4 , and two received a 3 in the Academic Journal Guide (AJG) 2018. The aim of the IOA15 list is to indicate the shared research interests of the faculty and to inform others about the composite research profile of the department, but it is not a list of the journals in which the faculty currently publishes. Thus, it represents an ambition for the future and a promise that faculty members will enter

\footnotetext{
1 https://cbsshare.cbs.dk/teams/afdelinger/ioa/Politikker/Forms/AllItems.aspx, accessed January 7, 2020.

2 The list includes: Academy of Management Journal, Academy of Management Review, Accounting, Organizations and Society, Human Relations, Journal of Management Studies, New Political Economy, Organization, Organization Science, Organization Studies, Public Administration: An International Quarterly, Public Management Review, Research Policy, Review of International Political Economy, Socio-Economic Review, and Sociological Review.
} 


\section{Valuation Studies}

the worldwide competition for publishing in the most prestigious journals in our field. ${ }^{3}$

Much of the supplementary text in the strategy document indicates awareness that this kind of strategy where publication efforts are aimed at a select group of journals is mainly a matter of impression management. It even promises to keep track of publications in all AJG journals, ensuring that there will be something to count. In the eyes of the dean (and most others), however, the template for a publication strategy includes such a shortlist. It is a sine qua non for appearing institutionally legitimate when the aspiration is to publish in the world's most prestigious journals. To support such aspirations, the department promises to teach its faculty how to get published in those journals, e.g., by holding seminars with the editors of these journals.

\section{Empowering management}

This trite publication strategy grows out of the fundamental presumption in modern society that everything important and valuable must be managed and organized. Before being manageable and able to be organized, it must be construed in such a way that allows it to be evaluated (at minimum, as good or bad), as management promises to make things better. My hunch is that nobody wondered why there was no collective publication strategy until the dean decided that publication was too important to be left to its own devices. At the same time, it is commonly acknowledged that academic publishing rests on a highly uncertain technology - akin to a lottery (Willmott 2021) - that severs any direct link between one's effort and the eventual outcome. Therefore, individual publication strategies are often of a hidden nature and primarily rationalized from past performance (Kreiner 2019) but, when explicated, they must assume a more prescriptive than descriptive stance.

The request to draw up an explicit publication strategy expresses a desire to manage, which also implies taking some responsibility for future publication practices. Such responsibility creates the need to develop some link between the available managerial buttons that managers press and performances of the managed faculty members. By and large, managers manage by allocating scarce resources in terms of money, career, and status. Thus, the dean may want to be able to reward departments with successful publishing performance with more money, more positions, more career opportunities, presuming that this will create an incentive for publishing more and better research. The challenge is to know who is performing well so that rewards are distributed fairly and rationally.

\footnotetext{
3 For data on the global article factory, see Angus Laing et al. (2021), "A New Future
} for Research". https://www.aacsb.edu/publications/link, accessed September 3, 2021. 
Meeting this challenge calls for heuristics, as valuation studies would predict. ${ }^{4}$ Across individual researchers and departments, publications are incommensurable. To be managed, they need to be made commensurable. The publication strategy serves such a purpose, reducing "singularities to comparabilities" (Esposito and Stark 2019: 7). Counting the number of publications in journals on the IOA15 list serves to measure success no matter the content of all such published and unpublished work. Ironically, the academic publication strategy encourages individual researchers to write to be counted, not to be read - which may not be a real choice anyway, as the fate of almost all publications is that only a few people read them.

As Esposito and Stark (2019) point out, the dean aspires to navigate the uncertainty inherent in academic institutions. This ability does not depend on the validity of the underlying heuristic. Even if we view it as being "simplistic, obscurantist, inaccurate, and subjective" (p. 3), it functions well as a heuristic because others (including our colleagues) observe us in terms of where we publish and how much. Anyone can find out the academic worth of everyone else without ever having read anything they have written. To produce statistics on publication performance relative to the publication strategy invites and enables the public to observe and evaluate the department in such terms. Having made it likely that others will view the department in such terms, the dean may now feel obliged and justified in doing the same.

We sense the strategic expediency in managing the complexity of universities in such a manner. Expediency rests on a certain measure of innocence - in March's (1999: 32) terms, the choice not to attend to the way life is - as opposed to ignorance, which is not knowing the way life is. Even if the faculty took the publication strategy seriously, it would seem to be a reckless deed to take managerial responsibility for future publication performance. The publication strategy is not likely to change the publication statistics in a positive direction. A lack of publications in top-tier journals is explained less by a lack of desire or attention, and more by a lack of luck, access, and connections. If that is true, a decision by more faculty members to submit to the same limited number of journals will have the immediate effect of increasing the competition, implying an even higher dependency on connections and luck. On average, the faculty will publish less than before in the target journals and probably publish less in other journals as well because time and effort are wasted on unsuccessful submissions. The most direct (but much slower) route to improving the publication statistics of the department would be a change in hiring practice, i.e., to hire faculty with strong publication records in the target journals.

${ }^{4}$ It is paradoxical, if understandable, that we feel discouraged when our theories seem to hold predictive power in our own lives. 


\section{Valuation Studies}

Also, the more indirect consequences of such a strategy are well explicated in the field of valuation studies. It may lead to a conventionalization of research topics, theories, and methods since the odds of publishing something slightly new will be slimmer. However, we should not forget that assessments of quality (also conventionalism) are essentially circular. True, the quality of my research is not dependent upon the journal in which it is published, were it not for the fact that this is exactly how others will socially assess quality and value. The reason is simple: By ranking journals as more and/or less valuable outlets, quality of content becomes an attribution that can be made based on the journal's rank. The circle is completed when attribution (quality of the publication) is used to explain and justify publication in a specifically ranked journal. In this sense, valuation is made possible because everyone may know the value of things without knowing anything about that which is being valued except where it was published. The dean, head of department, and my colleagues near and far will know my academic worth without ever wasting time on reading (or caring about) anything I have written. All they need to know is where I have published and how much. In essence, this form of valuation is an embodiment of the halo effect (Rosenzweig 2014).

Answering the heuristic question (where and how much you have published) for the unanswerable question of quality is in many places considered an irrational and human cognitive bias (Ariely 2008; Kahneman 2011). However, the legitimacy of management cannot be maintained were we to acknowledge the irrationality of the mechanisms on which it rests. The restoration of legitimacy is a task that requires another act of reductionism, namely, to instill a notion of reality in which heuristics and numbers are effective management tools.

In managing things beyond reach, we must act on the presumption that knowing such things is not necessary to managing them effectively. Critics point out that it is impossible to assess the effectiveness of such management - at least until it is too late to manage. Until then, the circular "logic" of the publication strategy is impossible to question. I will be seen as a mediocre academic if I have published little in the shortlisted journals; the accepted explanation for not publishing in the right journals is my mediocre academic qualities. Thus, smooth managers succeed by counting publications because they make a virtue of the circular logic involved, doing so in the interest of appearing to manage and control performance. Management is turned into the pretense of managing reality by numbers - unharmful, perhaps, but severely harmful in the multiple manners in which we must all contribute to the pretense of being managed effectively by such numbers. 


\section{Costs of maintaining the managerial pretense}

The publication complex illustrates the paradox of modern management. The dean wants to gain control and authority over publication practices, but to do so he surrenders all valuation authority to private organizations like the Chartered Association of Business Schools, which produces the AJG with ratings of journals in every field of research. The dean becomes a calculating machine (Dewey 1915), assessing performance using a simple algorithm. The precondition for this type of management is that reality is simple enough to be managed by algorithms. This is not, however, the reality that most of us experience. Consequently, in line with valuation studies, we should consider simplification as a task, not a solution. We should explore the nature of this task and how it is achieved in practice.

To be able to consider the rank of the publishing journal as an index for the quality of papers it publishes and the worth of its authors, we must trust editorial decisions to be objective, fair, and based solely on the stated editorial policies. Presumably, the process is shielded from personal biases by a cumbersome double-blind review procedure. However, it is often forgotten that editorial decisions are made by editors who are not unknowledgeable about the identity of the authors and who are also known to the authors. In this sense, there is certainly reciprocity in the valuation of manuscripts. Editorial decisions cannot be made without a practical judgment that also necessitates a value judgment as to what counts and how much. Letting the identity of the author influence the editorial decision is a value judgment, just as is ignoring this knowledge. It is merely in the final editorial decision that such value judgments are settled. All decisions, including editorial decisions, necessitate a circular logic (Dewey 1915). How much weight the editor puts on the reviews, the status of the author, and the agreeability of the research with the editor's tastes, for example, is a matter that is situationally determined and ultimately derived from the outcome of the editorial decision. The fact that the decision, in some sense, precedes the value judgment does not imply, at least not necessarily, that the decisions are bad or wrong, but only that they cannot be claimed to rest on objective and rational criteria (Kreiner 2020).

\section{Circularity in editorial decisions}

A recent article provides insights into the publication complex and how it is made to look simple. William L. Gardner (2020), editor-inchief of Group \& Organization Management, has explained why he ends up rejecting some articles after they have been through one or more rounds of revise and resubmit. The statistics are informative. $\mathrm{He}$ desk-rejected $47 \%$ of submissions, implying that $53 \%$ were sent to the 


\section{Valuation Studies}

journal's reviewers. For $54 \%$ of the reviewed articles, authors were invited to revise and resubmit their articles. Of these resubmitted articles, $73 \%$ ended up being accepted for publication. Ultimately, $27 \%$ of the reviewed and revised manuscripts ended up being rejected. Gardner made a content analysis of the reviews and the rejection letters concerning these ultimately rejected manuscripts. He raises the pertinent question of why, after all the effort authors, reviewers, and editors put in, were these articles finally rejected?

Initially, Gardner observes that "consensus among the reviewers is rare" (Gardner 2020: 2), leaving both the space and a need for editorial judgment. His content analysis revealed that manuscripts rejected in the end suffered from several serious problems. More than $88 \%$ of them fall victim to theoretical issues, including "inadequate specification and/or rationale for research questions/hypotheses" and "problems with research model." In more than $64 \%$ of cases, "concepts and operationalizations [were] not in alignment." More than $88 \%$ of them built on an "inadequate research design." As a final example, more than $70 \%$ of the revised manuscripts were criticized for a "lack of responsiveness/success in addressing reviewer concerns" (Gardner 2020: 380, tab. 1).

Based on the high frequency of the individual concerns, we can conclude that most papers exhibited many or most of these fundamental problems. Left with the puzzle as to why a manuscript with such an assortment of fundamental problems was accepted for review and subsequently invited to revise and resubmit, I venture to suggest that such value attributions reflect and change with the stipulated fate of the article. They are not reasons for the outcome, i.e., the rejection, but explanation and justification for a decision to such an effect. In terms of substance, it is unlikely that the quality of the texts deteriorated so drastically during the revision. Attributions more likely changed in light of the altered status of the manuscript, from having some potential to being unrepairable. If given any weight, inadequate research design would have killed the article long before the revise and resubmit stage. That it eventually killed the article indicates a change in relevance and attention at the expense of some other unknown quality that carried it into the review procedure. Killing the article was a practical judgment on the part of the editor that implied making a value judgment that the research design was unacceptable, making the decision consistent and justifiable.

Of course, my claim is not that the manuscripts should have been accepted. The decision to reject may very well have been wise and reasonable. Rather, I claim that we draw false lessons from experience when mistaking justification for reasons. These lessons are biased by the just-world hypothesis (Hafer 2007) - that the ill fate of a paper is deserved because it lacked the required quality. The effect is that measurable performance is rationalized, and the hierarchization of 
academia, universities, and scholars is legitimized. There were so many things that they could have done to get published, e.g., to provide proper rationale for research questions. Management needs to ensure that the next time a submission to the journal is made, these things will get done correctly, i.e., in ways found adequate by editors and reviewers. However, managers and bureaucrats risk barking up the wrong tree.

\section{Bureaucrats teaching scholars to write publishable articles}

Probably with the best of intentions, management wants to improve the faculty's track record in terms of publishing in the right journals by teaching them how to write publishable articles. Seminars are organized, and editors of high-ranking journals are invited to preach. Most conferences have this type of seminar on the agenda, just as most journals regularly print editorials that spell out what is required to get published - events that Willmott (2021) characterizes as selfcongratulatory. However, the lessons taught are inadequate and banal, if not perfectly wrong. They suffer from the same problems as Gardner (2020) ran into when mistaking justification for reasons.

We are taught that manuscripts should cover the relevant literature and represent it correctly - which is what almost $53 \%$ of the rejected manuscripts after the revise and resubmit process failed to do. The truth of this claim is not difficult to appreciate, but the degree to which these manuscripts differ substantively from the accepted ones cannot be taken for granted. Again, such assessments reflect a value judgment that is enforced by the practical judgment at hand, i.e., to reject or accept the manuscript (Dewey 1915). Because a rejection must be explicitly justified, such scholarly problems will be attributed to the manuscripts in the very same process as that in which the rejection is decided. They will be discounted if the outcome is different.

Such teaching based on a naive and simple model of editorial decision-making will unlikely improve the faculty's odds of getting published. A thought experiment will illustrate why. Suppose that the teaching proved successful, and all involved parties learned to write academic papers meeting the highest standards required by top journals and enforced by their editors. Editors would face the same practical judgment as before, i.e., to accept a few manuscripts and to reject the rest. Even if reviewers, who are not faced with such practical judgments, were generally to appreciate all the manuscripts as publishable, editors would still need to select a few - and be charged with the responsibility for legitimately justifying their editorial decisions. The practical judgment necessitates the invention of idiosyncratic criteria or weighting contingent qualities (like the identity of the author) more strongly. 


\section{Allegiance to the notion of governance}

The publication strategy is only one among many similar types of governance that universities adopt to look rational and efficient. For example, my department has also adopted a funding strategy, and all faculty members are expected to raise external funding for their research, both to increase the university's resource base and to enhance their careers. Public research councils are an important target for applying for funds, but the rejection rate is extremely high. Again, quality assessment of the application is based purely on its success, and since failure is the norm, there is seen to be a huge need for improving the quality of applications. Thus, there is an elaborate procedure for assuring the quality of applications that also involves the dean's office. Similarly, seminars are organized on how to write successful applications, presuming that competition between incommensurable research applications is fair, objective, and rational. Lessons here are as dubious as the lessons from unsuccessful publication efforts.

To my mind, the highest costs of this type of governance stem from the humiliation of critical scholars who must talk and act in ways that signal their allegiance to a ridiculously simple notion of reality for the dean to look as if he is managing departments and scholars. Such acquiescence to an institutional lie may be strategically expedient because the dean's decisions also involve a value judgment as to what counts and how much - a value judgment that is co-determined by decisions also made for other reasons. There is much about governance that should remind us of the emperor's new clothes, except that, in our case, the boy is required to act as the other weavers of rationale for governance, ratings, and rankings.

\section{The crack in the wall}

In conclusion, we celebrate ratings and rankings because they enable us to valuate things that we do not know; because they enable us to manage things that are beyond reach; because they order and stratify a complex and disorderly place like academia. Ratings and rankings are helpful - they help us navigate turbulent and uncertain situations, and they help us in the face of practical tasks like hiring and firing. They are also dangerous because they postulate a reality that makes them helpful in making the right decisions and conducting proper management. In such a reality, there is no opposition between writing to be counted and to be read, and management should be a matter of algorithmic calculation, relieving deans and others from making subjective judgments.

However, this postulated reality is markedly different from the reality in which we all practice - including the reality in which deans operate. This is where I sense a crack in the wall. The circularity in all forms of valuation processes may be hidden, but the valuator will 
never be relieved from making a value judgment when facing a practical situation that requires a choice. Dewey is right when he claims that we cannot act before deciding what counts and how much. In specific situations, there will always be more aspects and considerations than the numbers, rankings, and ratings. I owe my career to this truth.

A long time ago, I was lucky enough to be given a university position because another applicant with a much longer publication record handed in his application slightly after the deadline. Knowing the circularity of value judgments, also involving a judgment of what counts and how much, I take this episode as an indication that the head of department wanted to hire me, not the other person, because it would have been easy for him to include the slightly delayed application in the competition. Taking the deadline literally was a value judgment - and a contingent one.

Presumably, that judgment changed my career, but the point here is that management practice will necessarily involve practical judgments that also imply value judgments. There is no way of knowing, given the circumstances, if the head-on competition between two publication records, a short one and a long one, will necessarily recognize the long one as the winner. What we do know is that if the short one were to be given the job, it would have required further, more substantive justification, and therefore more work. We all know that many new concerns and criteria may be invoked in the assessment process (Kreiner 2012).

Even if ratings and rankings are easy and impeccable justification for managerial decisions, they are not necessarily decisive for the outcome. While we cannot trust our managers to be reflective in making such decisions, at least we know that decisions necessarily imply a value judgment that allows them, if motivated, to also make sensible decisions. Such sensibility might more likely be invoked by other means than acquiescence and strategic expediency. As Elangovan and Hoffman (2021) propose, we might experiment with remaining true to our identity as researchers, e.g., by writing to be read, not counted. After all, nobody reads journals any longer, because it is possible to effectively search and find relevant articles no matter where they are published. The procedural rationality that so dominates our thinking about management and practice will never promise a substantially rational outcome (March 1994). There is no way to prescribe a procedure for writing successful manuscripts and applications, and if such success is the aim, we must experiment with ways acting sensibly instead of searching for a foolproof way of aiming (Ryle 1949 [2000]). This is true for deans as well as scholars. So, let me close by quoting Cohen and March (1974) to the effect that it may be in the interest of college presidents (and deans) to encourage 
experimentation rather than conforming to the current norms of academic life:

College presidents who can forgo at least some of the pleasures of selfimportance in order to trade status for substance are in a strong position. Since leaders receive credit for many things over which they have little control and to which they contribute little, they should find it possible to accomplish some of the things they want by allowing others to savor the victories, enjoy the pleasures of involvement, and receive the profits of public importance. (p. 209)

\section{References}

Alvesson, Mats, and Betina Szkudlarek. 2021. "Honorable Surrender: On the Erosion of Resistance in a University Setting." Journal of Management Inquiry 30(4): 407-420.

Ariely, Dan. 2008. Predictably Irrational: The Hidden Forces That Shape Our Decisions. London: Harper Collins.

Baum, Joel A. C. 2011. "Free-Riding on Power Laws: Questioning the Validity of the Impact Factor as a Measure of Research Quality in Organization Studies." Organization 18(4): 449-466.

Cohen, Michael D, and James G. March. 1974. Leadership and Ambiguity: The American College President. New York: McGraw-Hill.

Dewey, John. 1915. "The Logic of Judgments of Practise." Journal of Philosophy, Psychology and Scientific Methods 12(19): 505-523.

Elangovan, A. R., and Andrew J. Hoffman. 2021. "The Pursuit of Success in Academia: Plato's Ghost Asks 'What then?'” Journal of Management Inquiry 30(1): 68-73.

Esposito, Elena, and David Stark. 2019. "What's Observed in a Rating? Rankings as Orientation in the Face of Uncertainty." Theory, Culture \& Society 36(4): 3-26.

Gardner, William L. 2020. "Why I Rejected Your R\&R Submission and What You Could Have Done to Secure an Acceptance." Journal of Management Inquiry 29(4):378-384.

Hafer, Carolyn L. 2007. "Just-World Hypothesis.” In Encyclopedia of Social Psychology, edited by R. F. Baumeister and K. D. Vohs, 514-516. Thousand Oaks, CA: SAGE Reference.

Kahneman, Daniel. 2011. Thinking, Fast and Slow. London: Allen Lane.

Kreiner, Kristian. 2012. "Organizational Decision Mechanisms in an Architectural Competition." In Research in the Sociology of Organizations, 36: "The Garbage Can Model of Organizational Choice: Looking Forward at Forty", edited by Alessandro Lomi and J. Richard Harrison, 399-429. Bingley, UK: Emerald Books.

Kreiner, Kristian. 2019. “On Publication Strategies.” Sociologica 13(1): 2931.

Kreiner, Kristian. 2020. "Pick the Winner, So You Can Then Choose the Reasons: Epistemic Dissonance in Architecture Competitions.” In The 
Performance Complex: Competitions and Valuations in Social Life, edited by David Stark, 31-54. Oxford: Oxford University Press.

Laing, Angus, Katy Mason, Ansgar Richter, and Wilfred Mijnhardt. 2021. "A

New Future for Research", AACSB. https://www.aacsb.edu/insights/ articles/2021/08/a-new-future-for-research, accessed September 3, 2021.

March, James G. 1994. A Primer on Decision Making: How Decisions Happen. New York: Free Press.

March, James G. 1999. "Science, Politics and Mrs. Gruenberg." In The Pursuit of Organizational Intelligence, edited by James G. March, 355362. Oxford: Blackwell.

Ossandón, José. 2021. “University Management after Valuation Studies: Carving a Practice in between the Offended Native, the Anxious Scholar, and the Useless Practitioner." Valuation Studies, 8(2):61-72.

Pilkey, Orrin H., and Linda Pilkey-Jarvis. 2007. Useless Arithmetic: Why Environmental Scientists Can't Predict the Future. New York: Columbia University Press.

Rosenzweig, Phil. 2014. The Halo Effect ... and the Eight Other Business Delusions That Deceive Managers, 2nd edn. London: Simon \& Schuster. Ryle, Gilbert. 1949 [2000]. The Concept of Mind. London: Penguin Books.

Tsang, Eric W. K. 2013. "Is This Referee Really My Peer? A Challenge to the Peer-Review Process." Journal of Management Inquiry 22(2): 166-171.

Willmott, Hugh. 2021. "Critical Essay: Blinding Faith - Paradoxes and Pathologies of Opacity in Peer Review.” Human Relations, online first.

Kristian Kreiner is a professor emeritus at Copenhagen Business School, Department of Organization. He has conducted multiple empirical studies of management and decision-making in complex and ambiguous realities. Rather than considering such realities as a sign of managerial fiasco, he has explored the possibility for meaningful management when complexity and ambiguity are inevitable conditions for human action. Most recently, he has studied architecture competitions and how juries choose the winners. He has also written critically about project management and the perverse manner in which this field learns false lessons from experience. 
